\title{
Additive Manufacturing of Complex-Shaped Graded TiC/Steel Composites
}

\author{
Asaf Levy ${ }^{1}$, Aslan Miriyev ${ }^{2, *}$, Amy Elliott $^{3}$, Sudarsanam Suresh Babu ${ }^{4}$, Nachum Frage $^{1}$
}

${ }^{1}$ Department of Materials Engineering, Ben-Gurion University of the Negev, P.O. Box 653, Beer-Sheva, 8410501, Israel

${ }^{2}$ Department of Mechanical Engineering, Columbia University in the City of New York, 500W $120^{\text {th }}$ St., Mudd 220, New York, NY, 10027, USA

Corresponding Author, E-mail: aslan.miriyev@columbia.edu

${ }^{3}$ Manufacturing Demonstration Facility, Oak Ridge National Laboratories, 1 Bethel Valley Road P.O. Box 2008, Oak Ridge, TN, 37831, USA

4 Department of Mechanical, Aerospace and Biomedical Engineering, University of Tennessee, Knoxville, TN, 37996, USA

Keywords: Additive manufacturing, ceramic metal composites, graded materials, steel, titanium carbide.

\begin{abstract}
Complex-shaped $\mathrm{TiC}_{x}$ ceramic preforms with a gradient of carbon content in the titanium carbide phase ( $x$ changes from 0.7 to 0.98 ) were fabricated for the first time by Binder jet 3D printing technology. The complex-shaped preforms were infiltrated with molten carbon steel (0.7 wt.\%C). Thermodynamic considerations showed that carbon could be transferred from titanium carbide to steel and vice versa according to the initial concentration of carbon (activity) in both phases. After infiltration, solidification and slow cooling, a microstructural gradient was obtained throughout the steel matrix from ferrite, in the region where the steel was in contact with titanium carbide of low carbon content $(x=0.7)$, to pearlite, in the region where the steel underwent interactions with stoichiometric titanium carbide $(x=0.98)$. After annealing at $900^{\circ} \mathrm{C}$ and quenching in oil, a structural gradient in the steel matrix from ferrite to martensite was obtained, resulting in a hardness gradient of 700-1600 HV. The suggested processing approach allows for fabrication of complex-shaped graded composites with the desired property gradient suitable for a wide range of practical applications.
\end{abstract}




\section{Introduction}

Implementation of a graded materials concept provides material designers with additional degrees of freedom for designing and manufacturing the material components required to meet specific goals. Many approaches have been employed for the fabrication of ceramicmetal composites (cermets) in which the metal-to-ceramic ratio varies gradually along certain pre-determined directions as a result of free infiltration of a porous ceramic preform with graded porosity [1-5]. An approach for the fabrication of graded cermets, based on a composition-dependent interaction between the ceramic phase and the molten metal, was previously suggested and implemented for the fabrication of graded titanium carbide/steel cermets [6]. In the present study, this approach was applied to a system consisting of the titanium carbide phase of various carbon content and plain carbon steel $(0.7$ wt.\%C). Titanium carbide displays a wide stoichiometric domain from 33 at.\%C $\left(\mathrm{TiC}_{0.48}\right)$ to 49 at.\%C $\left(\mathrm{TiC}_{0.98}\right)$, with its thermodynamic properties strongly depending on the composition. It was shown that the carbon activity in the ceramic phase varied from 1 for titanium carbide $\mathrm{TiC}_{0.98}$ to the extremely small value of about $10^{-6}$ for titanium carbide with the lowest carbon content [7] (with graphite and $\alpha-\mathrm{Fe}$ being the standard states). General thermodynamic considerations showed that the interaction between the stoichiometric titanium carbide and the molten steel with 0.7 wt. $\% \mathrm{C}$ (in which the carbon activity at $1550^{\circ} \mathrm{C}$ was about $10^{-2}$ ) led to enrichment of the steel by carbon (up to $0.8-1.0 \mathrm{wt} . \% \mathrm{C}$ ), while the interaction of steel with titanium carbide of lower carbon content led to significant carbon depletion of the steel (less than $0.1 \mathrm{wt} . \% \mathrm{C}$ ) [8]. It is well known that carbon content in molten steel dictates the microstructure of the steel matrix of infiltrated composites after solidification and cooling. The mechanism of microstructure evolution includes carbon diffusion from the ceramic phase to the steel, or vice versa, according to the initial carbon activity in the both phases. The microstructure of the steel after solidification and slow cooling was determined by assessing the final carbon concentration. Appropriate heat treatment of the composite could lead to desired phase 
transformation and mechanical properties evolution in the steel matrix of the infiltrated composites. It was established that the metallic matrix of composites fabricated with stoichiometric titanium carbide $\left(\mathrm{TiC}_{0.98}\right)$ displayed a pearlitic microstructure, while for composites with ceramic preforms made of $\mathrm{TiC}_{0.7}$, the microstructure of the metal matrix was mostly ferritic [6]. These microstructural changes in the metal matrix, occurring over a relatively narrow change of the carbon content in the titanium carbide phase, open the possibility of producing graded composites. This possibility is based on the effect of carbon content in the metal matrix on the microstructure and properties of the matrix after quenching. While quenching hardly changes the hardness value of the ferritic matrix, this trait significantly increases in the pearlitic matrix due to the formation of martensite. Thus, by varying the titanium carbide composition along certain directions of the ceramic preform, with subsequently infiltration with molten steel and quenching of the infiltrated composites, a graded material can be generated, in which hardness varies according to microstructural changes in the metal matrix.

A thermodynamic analysis of the $\mathrm{TiC}_{x} /$ steel system that takes into account carbon activity in both phases [7,9] allowed to design the final composition of each layer of the infiltrated composite and hence, its final properties. To fabricate graded composite parts with complex geometries, an additive manufacturing (AM) approach for ceramic preform preparation can be applied [10]. Here, a ceramic preform with complex geometries would have to be infiltrated by molten carbon steel to produce TiC/steel composites. Several different AM techniques are used today to fabricate ceramics parts [11]. Previously, yttria-zirconia structures with precise complex geometries [12], as well as $\mathrm{SiC}$ [13] (subsequently infiltrated with $\mathrm{Si}$ to form $\mathrm{Si} / \mathrm{SiC}$ composite) and $\mathrm{Al}_{2} \mathrm{O}_{3}$ [14,15] parts, were fabricated using selective laser sintering. Stereolithography has been reported as a processing route for the production of turbine airfoils made of fused silica [16], microwave guides made of zirconia [17], hydroxyapatite bone implants [18] and honeycomb silicone oxicarbide structures for various applications [19]. 
Studies of extrusion free-forming of silicon nitride, lead-zirconate-titanate, lead-magnesium niobate [20] and alumina [20-22] have been reported. Presently, however, the most widely applied ceramic additive manufacturing technique is 3D-printing. Examples of 3D-printing of ceramics include dental restorations [23], miniature heat exchangers [23-25], impellers [26], and micro-pillar arrays [27] for direct 3D-printing (i.e. direct deposition of the ceramic suspension), as well as bone implants [28] and macrocellular structures [29,30] by the indirect technique, also known as binder jetting.

Binder jetting uses several ejection nozzles for scalable parallel application of a binder to a powder in the powder bed. High deposition speed, along with no need for a high-powered energy source, makes binder jetting a fast and low cost process. One of the most important benefits of this approach is the ability to produce parts with geometries of any complexity without the need for support structures. Binder jetting allows for the arrangement of several separated or interconnected (assembly) parts, arrayed and stacked in the powder bed, thereby greatly increasing the number of parts printable in a single print job [31,32]. After printing, the part can be infiltrated by a molten metal, which imparts special properties to the final product $[10,11]$. Binder jetting has been used for fabrication of many ceramic-based composites, such as $\mathrm{Si} / \mathrm{SiC}$ [29,30], $\mathrm{Al}_{2} \mathrm{O}_{3} / \mathrm{Cu}$ [33] and $\mathrm{TiAl}_{3} / \mathrm{Al}_{2} \mathrm{O}_{3}$ [34]. TiC/TiCu composites have been produced using 3D-printing of starch and subsequent infiltration with $\mathrm{TiCu}$ alloy [35]. 3D-printing of TiC structures from $\mathrm{TiC}$ powder has, however, not yet been reported.

Here, we report on an approach for the fabrication of fully dense graded titanium carbide/steel composites with tailored properties by binder-jet 3D-printing of complex-shaped $\mathrm{TiC}$ structures and their free infiltration with molten steel.

\section{Materials and Methods}

\section{Materials}


Non-stoichiometric $\operatorname{TiC}_{x}(x=0.7,0.8,0.9,0.98)$ powders were prepared by mixing $\mathrm{TiC}_{0.98}$ powder (CERAC, 99.5\% pure, 44 microns) and Ti powder (Alfa Aesar, 99\% pure, 44 microns) in appropriate ratios by ball milling (boron carbide crucible and grinding balls) for 1 hour. SAE1070 steel (C - 0.65-0.75\%, Mn - 0.6-0.9\%, P < 0.040\%, $\mathrm{S}<0.050 \%)$ was used for infiltration of the ceramic preforms.

\section{Design of the final composition}

To design the final composition of the composite, thermodynamic equations of carbon activity in steel and carbide, described in previous work [9,36], were used for the computational calculation of $\mathrm{TiC} /$ steel reaction products. The calculation was performed using equations for four titanium carbide compositions $\left(\mathrm{TiC}_{0.7}, \mathrm{TiC}_{0.8}, \mathrm{TiC}_{0.9}, \mathrm{TiC}_{0.98}\right)$ and $\mathrm{SAE} 1070$ (0.7 wt.\%C) written in Matlab software. The euqations are also provided in the "Thermodynamic calculations" section of the Supplementary Materials.

\section{Processing}

Several simple- and complex-shaped graded parts, consisting of four layers with various titanium carbide compositions $\left(\mathrm{TiC}_{0.7}, \mathrm{TiC}_{0.8}, \mathrm{TiC}_{0.9}, \mathrm{TiC}_{0.98}\right)$, were printed using the ExOne X1-Lab binder jet machine at the Manufacturing Demonstration Facility (MDF), Knoxville, TN. Key parameters of the printing process were as follows: The feed powder to layer ratio was 2.5:1, each printed layer was 100 microns thick, the powder spread velocity was 0.5 $\mathrm{mm} / \mathrm{sec}$, and binder saturation and powder packing were $80 \%$ and $35 \%$, respectively. The ExOne commercial ProMetal R-1 Binder was used for all printed parts. The obtained green body parts (see below) were free-infiltrated with SAE1070 steel in a vacuum furnace $\left(<10^{-4}\right.$ torr). The infiltration process included two heating stages. First, heating and holding at $1400^{\circ} \mathrm{C}$ for 4 hours to enable the synthesis of $\mathrm{TiC}_{x}$ from the mixed powders, and then heating and holding at $1550^{\circ} \mathrm{C}$ for 15 minutes. After cooling in the furnace, the samples were cut, 
mounted and polished for further study. After infiltration, the samples were heat-treated at $900^{\circ} \mathrm{C}$ for 30 minutes and quenched in oil.

\section{$3 D$-printing process}

Binder jetting is an AM process that utilizes inkjet technology to deposit a binder into a powder bed. The process starts with a spreading of the powder with a roller into a $\sim 100$ micron thick layer. Then, an inkjet print head passes over the layer and deposits the binder into a two-dimensional pattern corresponding to the cross section of a specific layer of the part. The build area is then lowered by the desired layer thickness, more powder is spread, and the process continues at the next layer until the part is fully printed. Due to the chemistry of the binder, the part must then be cured at $200^{\circ} \mathrm{C}$ while remaining in the powder bed. Once cured, the part is in the "green" state and can be removed from the powder bed.

\section{Characterization}

The microstructure of the specimens before and after infiltration and quenching was evaluated using an optical microscope (Zeiss, Aalen, Germany) and a High Resolution Scanning Electron Microscope (HRSEM, JEOL JSM 7400F). Phase composition was determined by Xray diffraction (XRD) using a Rigaku RINT 2100 (Tokyo, Japan) diffractometer with $\mathrm{Cu} \mathrm{K} \alpha$ radiation $(\lambda=0.1542 \mathrm{~nm})$. The operating parameters were $40 \mathrm{kV}$ and $40 \mathrm{~mA}$, with a $2 \theta$ step size of 0.033 . The XRD patterns were analyzed using the whole pattern fitting approach with MDI Jade 2010 software (MDI, Livermore, CA). Prior-to-infiltration samples of each composition, synthesized at $1400^{\circ} \mathrm{C}$ for 4 hours, were ground to powder for XRD analysis in order to confirm that the desired stoichiometry was achieved. XRD examination of the samples after infiltration was carried out on both sides of the composite, where the initial titanium carbide stoichiometry was $\mathrm{TiC}_{0.7}$ and $\mathrm{TiC}_{0.98}$, respectively. Vickers hardness measurements were performed using a Buehler Micromet 2010 apparatus under a $2 \mathrm{~kg}$ load. 


\section{Results and Discussion}

Due to the impressive geometrical versatility of the printed parts, infiltration-oriented profile and highly economical operation, binder jetting was used for fabricating graded complexshaped TiC parts. The fabrication process used is illustrated in detail in Figure 1.

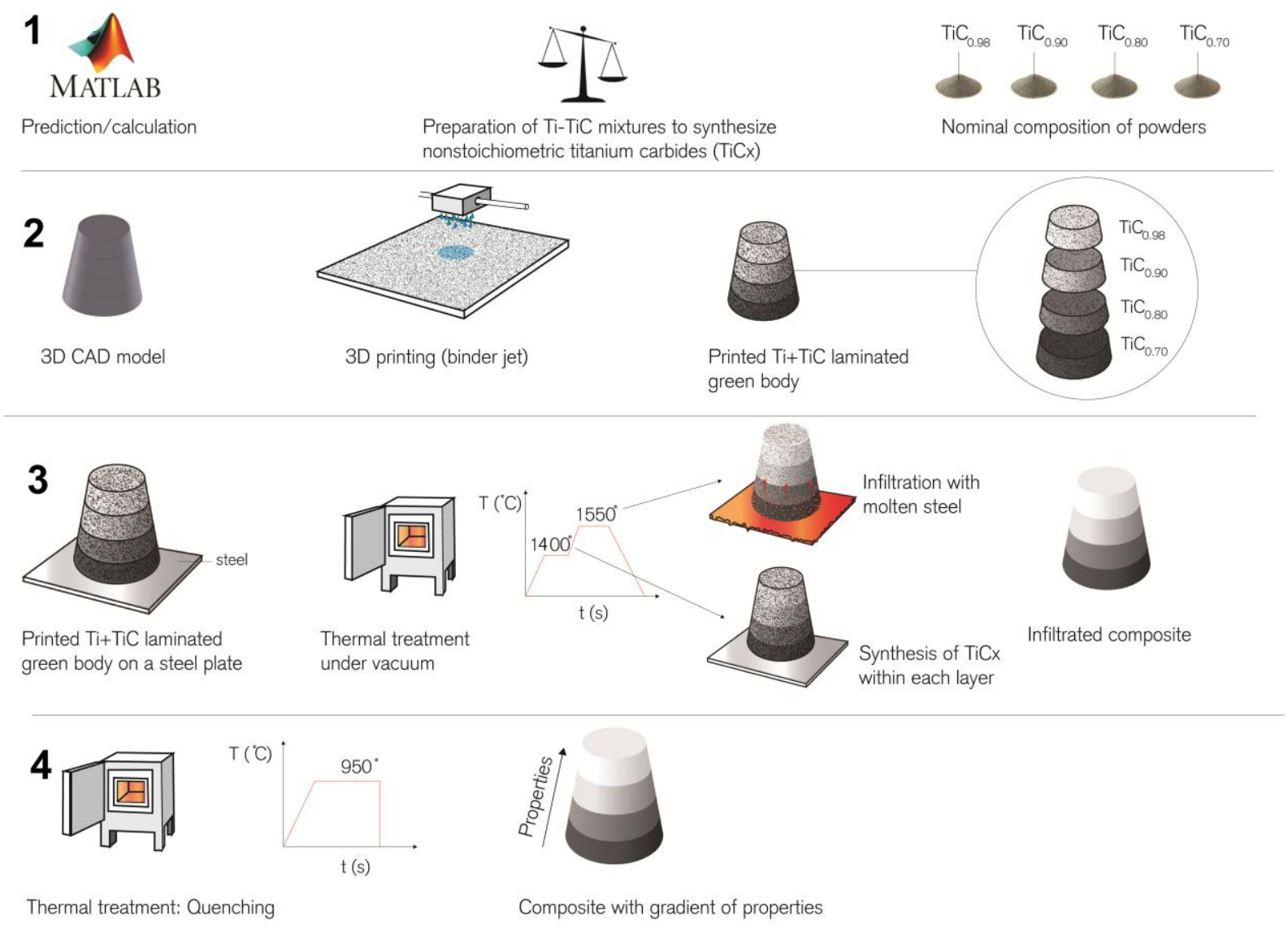

Figure 1. Fabrication of fully dense 3D-printed graded TiC/steel composite.

To create varying spatial composition based on the desired $\mathrm{TiC}_{x}$ stoichiometry profile (calculated by thermodynamic analysis), $\mathrm{TiC}$ and $\mathrm{Ti}$ powders with various $\mathrm{TiC} / \mathrm{Ti}$ ratios, corresponding to $\mathrm{TiC}_{\mathrm{x}}$ compositions with $x=0.7,0.8,0.9,0.98$, were mixed and heat-treated at $1400^{\circ} \mathrm{C}$ for 4 hours. XRD analysis of the heat-treated ceramics showed no evidence of free Ti, with the lattice parameters estimated from the diffraction spectra being $0.4325,0.43306$, 
0.43286 and $0.4328 \mathrm{~nm}$ for the above-mentioned mixtures presenting $x$ values of $0.7,0.8,0.9$, 0.98 , respectively. The obtained results were in a good agreement with those reported in the literature [8] (Figure 2) and confirmed that the applied heat treatment allowed complete transformation of the Ti-TiC powder mixtures into a single titanium carbide phase of the various desired compositions.

The Ti-TiC mixtures were used for 3D-printing of four-layered parts with various geometries, such as a hollow and a full cone, a helical gear, a "spider web" lattice truss, "Lego bricks" and simple cubes (Figure 3 and Supplementary Movie S1).

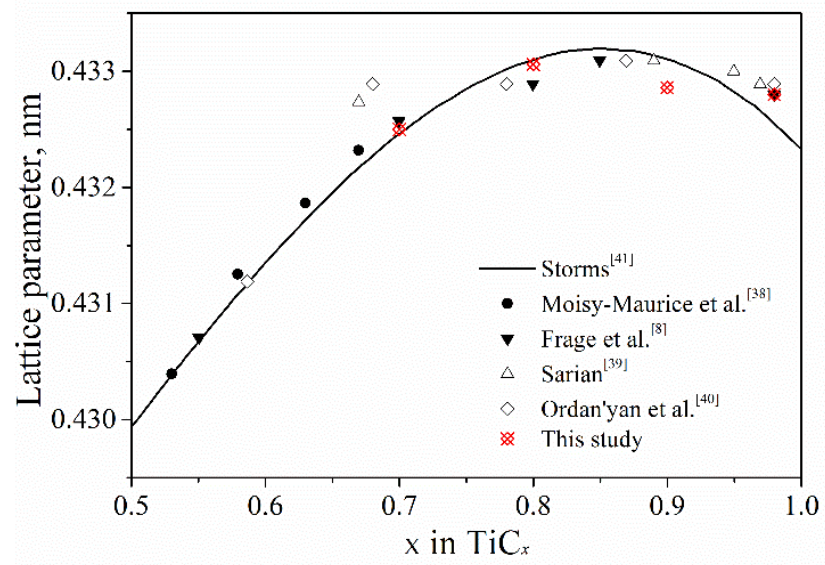

Figure 2. Lattice parameters of the titanium carbide phase as a function of its composition [8,37-40].

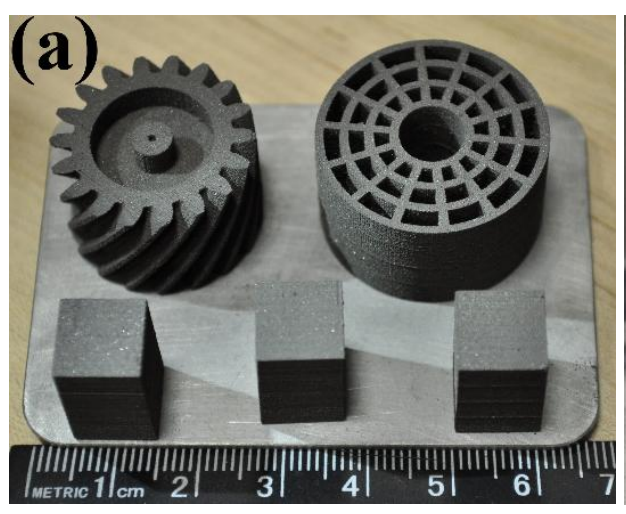

(c)

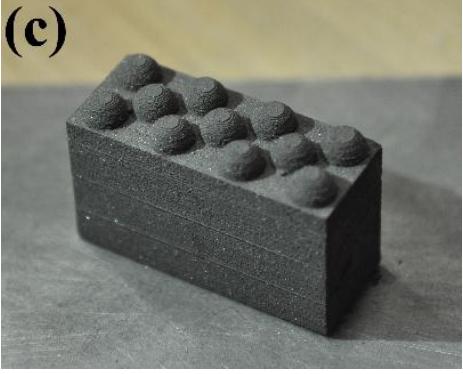

(d)

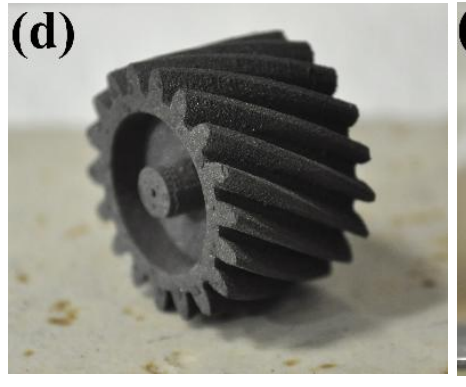

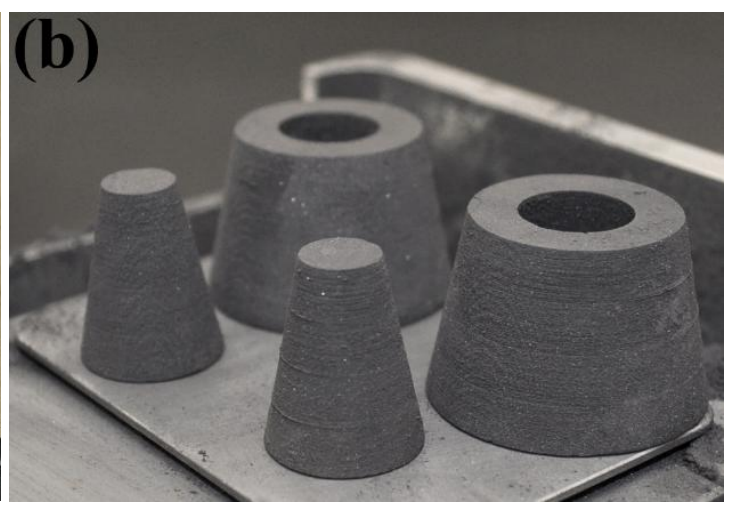

(e)

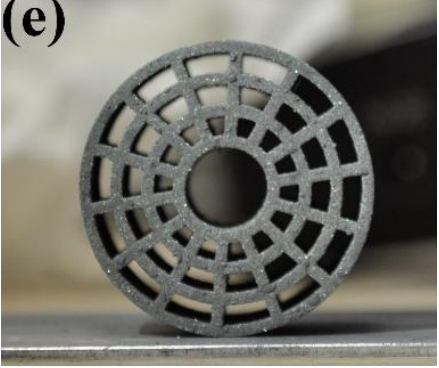


Figure 3. 3D-printed $\mathrm{TiC}_{\mathrm{x}}$ preforms with various geometries: a) helical gear, "spider web" lattice truss and simple cubes; b) hollow and full cones; c) "Lego brick"; d) helical gear; e) "spider web" lattice truss.

The graded preforms were heat-treated at $1400^{\circ} \mathrm{C}$ for $\mathrm{TiC}_{x}$ formation and infiltrated with molten steel at $1550^{\circ} \mathrm{C}$. The microstructure of each layer of the infiltrated specimens was examined before and after quenching (Figures 4 and 5, respectively). The microstructure consisted of smooth-edged ceramic grains, surrounded by the steel matrix. This feature is attributed to the partial dissolution of the ceramic particles in the molten metal [9]. The layer with $\mathrm{TiC}_{0.7}$ displayed a mostly ferritic microstructure (Figure $4 \mathrm{a}$ ), while the amount of pearlite phase increased as one approached the layer with $\mathrm{TiC}_{0.98}$ (Figure $4 \mathrm{~b}$ and $\mathrm{c}$ ), where steel mostly presented a pearlitic microstructure (Figure 4d).
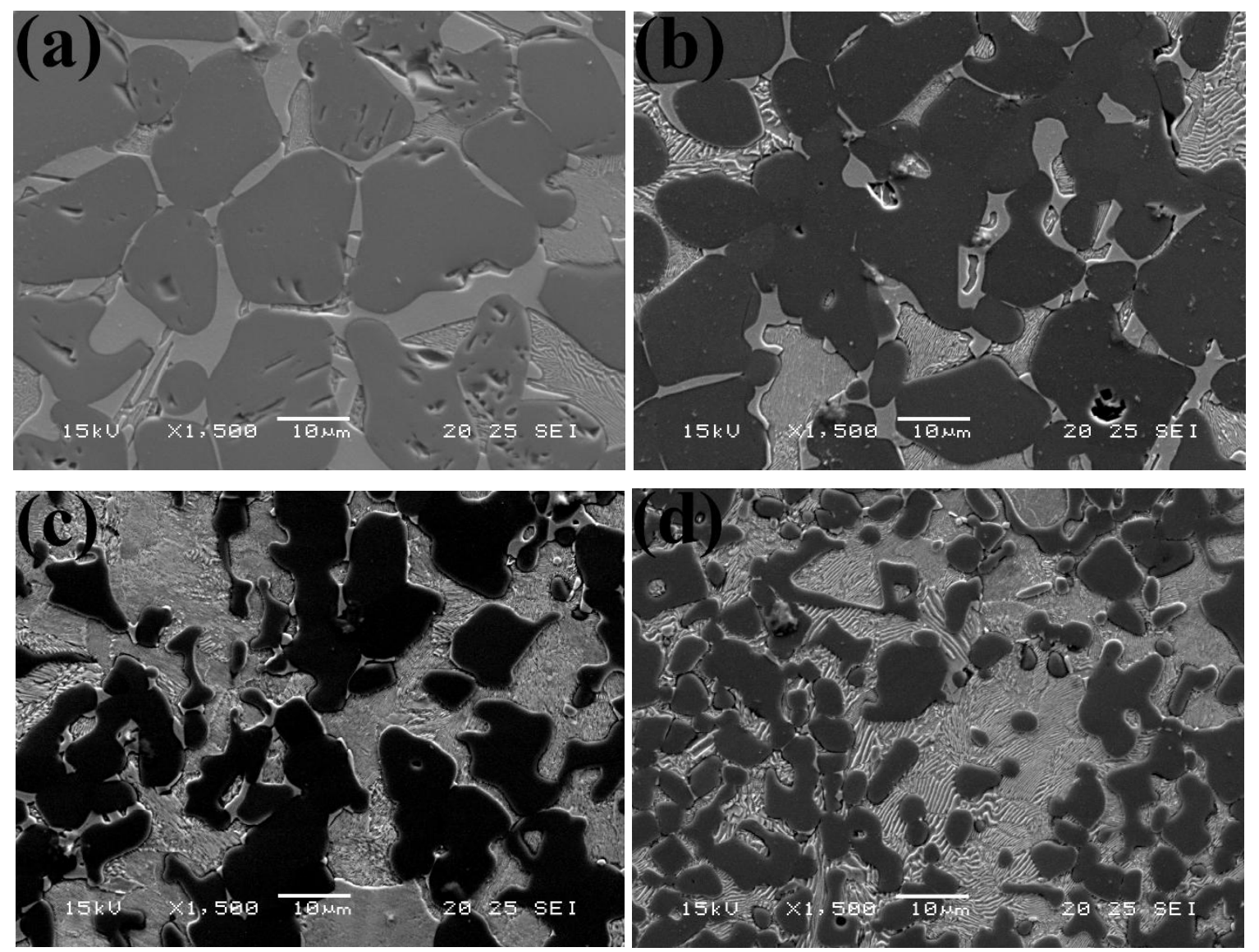

Figure 4. SEM images of polished and etched (Nital, 4\%) composite layers with various initial compositions of titanium carbide before quenching: (a) $x=0.7$, (b) $x=0.8$, (c) $x=0.9$ and (d) $x=0.98$. 
Grain growth of the ceramic phase with initially low carbon content was observed. It is well known that mass transport and grain growth during sintering of titanium carbide powder strongly depends on its stoichiometry. Significant grain growth was observed for titanium carbide with low carbon content, even at relatively low sintering temperatures [41]. In our case, synthesis of titanium carbide of the desired stoichiometry was conducted at $1400^{\circ} \mathrm{C}$ for 4 hours. Evidently, these conditions were sufficient to provide the grain growth observed.

Gradually increasing the carbon content in steel from the $\mathrm{TiC}_{0.7}$ side of the composite towards the $\mathrm{TiC}_{0.98}$ side was reflected in the post-quenching microstructure (Figure 5). The microstructure mostly consisted of un-transformed $\alpha$ ferrite on the $\mathrm{TiC}_{0.7}$ side (Figure 5a), while fine martensitic microstructure was clearly observed on the $\mathrm{TiC}_{0.98}$ side (Figure $5 \mathrm{~d}$ ).
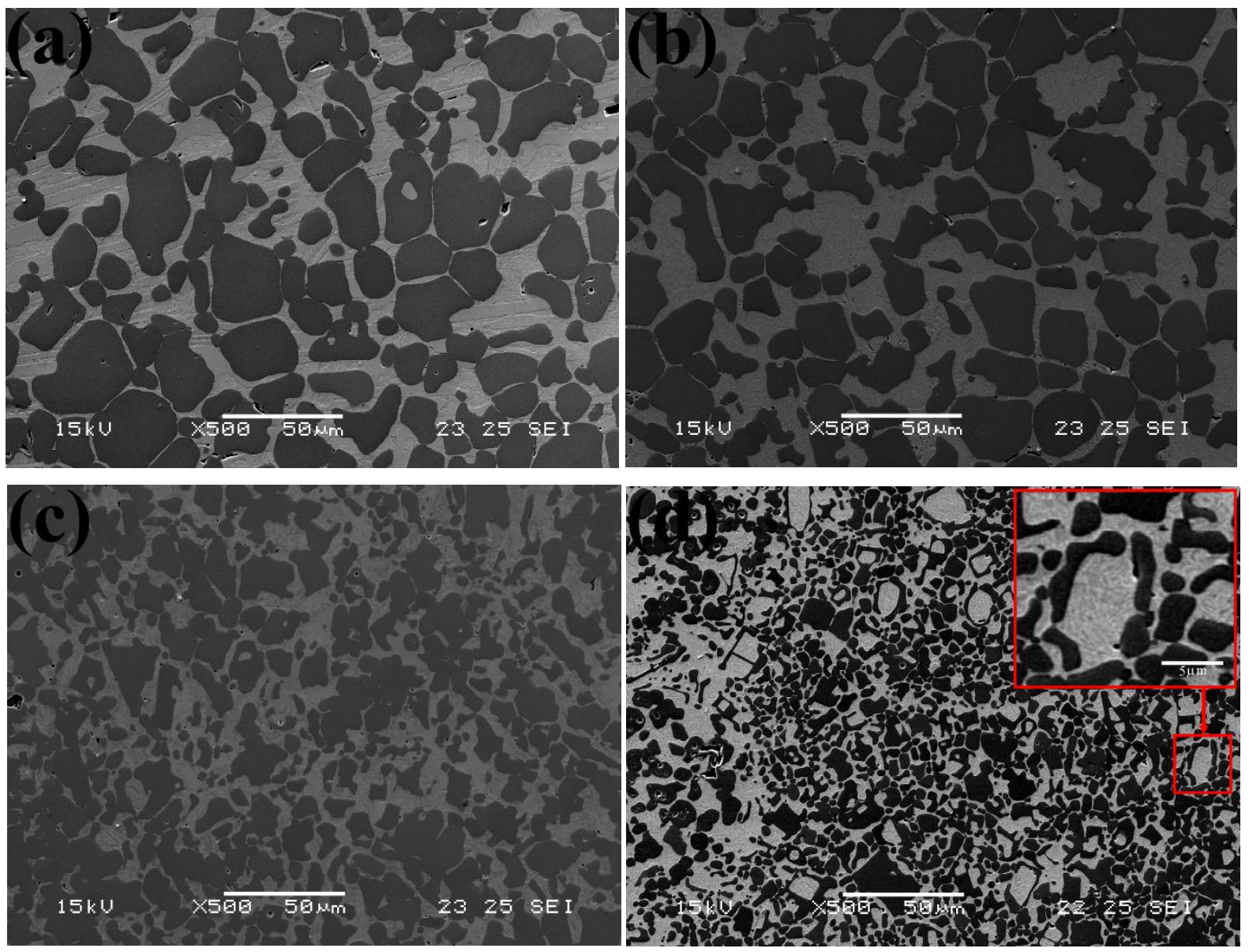

Figure 5. SEM images of polished and etched (Nital, 4\%) composite layers with various initial compositions of titanium carbide after quenching: (a) $x=0.7$, (b) $x=0.8$, (c) $x=0.9$ and (d) $x=0.98$. The magnified image $(\mathrm{x} 5000)$ in $(\mathrm{d})$ shows the fine martensite structure in the vicinity of $\mathrm{TiC}_{0.98}$ in detail. 
The lattice parameter calculated from the XRD spectrum taken from the $\mathrm{TiC}_{0.7}$ layer after infiltration corresponded to that of the $\mathrm{TiC}_{0.9}$ layer. According to the $\mathrm{EDS}$ analysis, the $\mathrm{Ti}$ content in the steel that was in contact with $\mathrm{TiC}_{0.7}$ was about $0.8 \mathrm{wt} . \%$. Before quenching, hardness values along the composite varied only slightly from 700 to $1000 \mathrm{HV}$ on the $\mathrm{TiC}_{0.7}$ and $\mathrm{TiC}_{0.98}$ sides, respectively. After quenching, the hardness values in the carbon-rich (i.e., martensite-rich) layers significantly increased up to $1600 \mathrm{HV}$, providing a $700 \div 1600 \mathrm{HV}$ gradient along the composite (Figure 6).

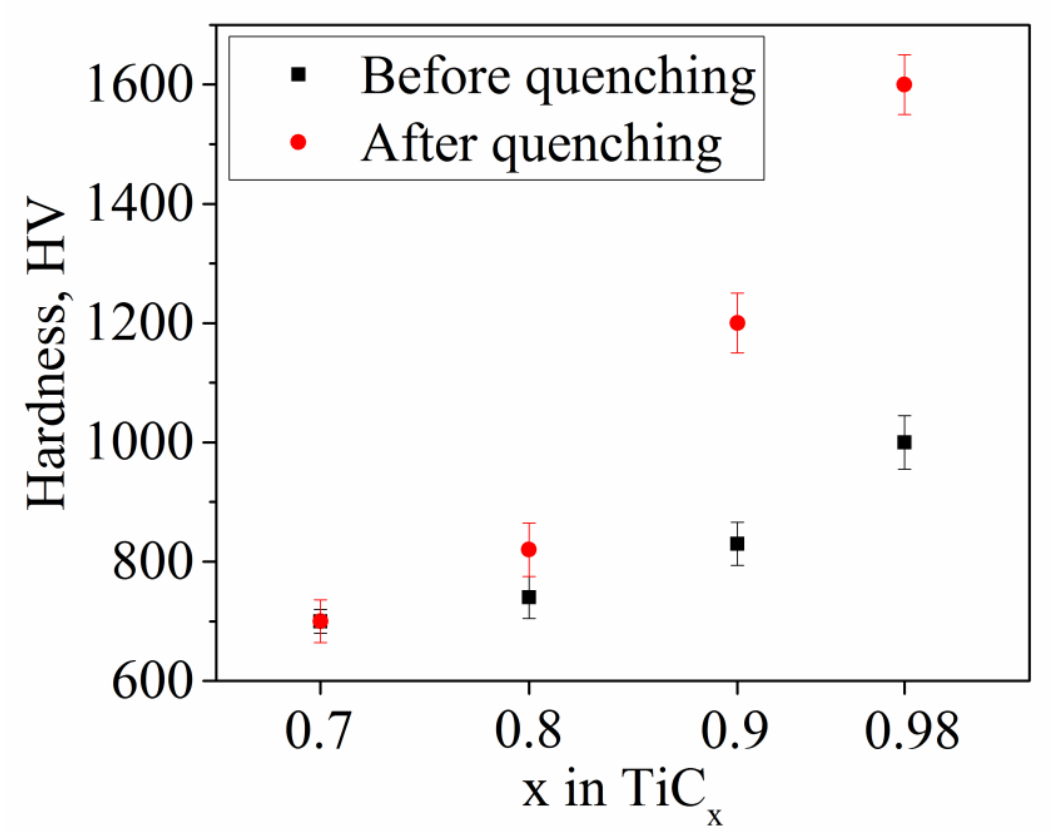

Figure 6. Hardness values of the composite layers as a function of titanium carbide composition before and after quenching.

In this article, we designed TiC/steel composites with tailored gradients of properties using thermodynamic predictions and, for the first time, fabricated fully dense complex-shaped parts by binder-jet 3D-printing and free infiltration. This approach opens the door for advanced applications in tooling, wear, aerospace, ballistic and other fields. 


\section{Acknowledgements}

This report is based upon work supported by the U.S. Department of Energy ${ }^{\mathrm{a}}$, Office of Science, Office of Advanced Manufacturing, under contract number DE-AC05-00OR22725. The authors express thanks to Mr. Drim Stokhuijzen for assistance with illustrations.

\section{References}

[1] Frage N., Levin L., Dariel M.P., Graded boron carbide-aluminum cermets, in: Trumble K., Bowman K., Reimanis I. E., Sampath S. (Eds.), Funct. Graded Mater. 2000 Proc. 6th Int. Symp. Funct. Graded Mater., American Ceramic Society, Estes Park, 2000.

[2] Seidman Y., Frumin N., Frage N., Dariel M. P., Two-phase TiC+TiB2 graded ceramic preforms, in: Trumble K., Bowman K., Reimanis I. E., Sampath S. (Eds.), Funct. Graded Mater. 2000 Proc. 6th Int. Symp. Funct. Graded Mater., American Ceramic Society, Estes Park, 2000.

[3] Y. Miyamoto, W.A. Kaysser, B.H. Rabin, A. Kawasaki, R.G. Ford, Functionally graded materials: Design, processing and applications, (1999).

[4] G. Kapelski, A. Varloteaux, A Technique of Elaboration of Functionally Graded Cermets, Mater. Sci. Forum. 308-311 (1999) 175-180. doi:10.4028/www.scientific.net/MSF.308-311.175.

[5] M. Dröschel, R. Oberacker, M.J. Hoffmann, W. Schaller, D. Munz, Porosity Graded Silicon Carbide Evaporator Tubes for Gasturbines with Premix Burners, in: Ceram. Mater. Components Engines, Wiley-VCH Verlag GmbH, Weinheim, Germany, 2007: pp. 531-536. doi:10.1002/9783527612765.ch90.

[6] S. Sabatello, N. Frage, M.. Dariel, Graded TiC-based cermets, Mater. Sci. Eng. A. 288

\footnotetext{
${ }^{a}$ This manuscript has been authored by UT-Battelle, LLC under Contract No. DE-AC05-00OR22725 with the U.S. Department of Energy. The United States Government retains and the publisher, by accepting the article for publication, acknowledges that the United States Government retains a non-exclusive, paid-up, irrevocable, worldwide license to publish or reproduce the published form of this manuscript, or allow others to do so, for United States Government purposes. The Department of Energy will provide public access to these results of federally sponsored research in accordance with the DOE Public Access Plan (http://energy.gov/downloads/doe-public-access-plan).
} 
(2000) 12-18. doi:10.1016/S0921-5093(00)00889-3.

[7] N. Frage, L. Levin, E. Manor, R. Shneck, J. Zabicky, Iron-titanium-carbon system. II. Microstructure of titanium carbide $(\mathrm{TiCx})$ of various stoichiometries infiltrated with iron-carbon alloy, Scr. Mater. 35 (1996) 799-803. doi:10.1016/1359-6462(96)00230-8.

[8] N. Frage, N. Froumin, M.. Dariel, Wetting of TiC by non-reactive liquid metals, Acta Mater. 50 (2002) 237-245. doi:10.1016/S1359-6454(01)00349-4.

[9] N. Frage, Interaction between nonstoichiometric titanium carbide and Fe-C alloys, Metall. Mater. Trans. B. 30 (1999) 857-863. doi:10.1007/s11663-999-0090-x.

[10] I. Gibson, D.W. Rosen, B. Stucker, Additive Manufacturing Technologies, Springer US, Boston, MA, 2010. doi:10.1007/978-1-4419-1120-9.

[11] N. Travitzky, A. Bonet, B. Dermeik, T. Fey, I. Filbert-Demut, L. Schlier, et al., Additive Manufacturing of Ceramic-Based Materials, Adv. Eng. Mater. 16 (2014) 729_ 754. doi:10.1002/adem.201400097.

[12] P. Bertrand, F. Bayle, C. Combe, P. Goeuriot, I. Smurov, Ceramic components manufacturing by selective laser sintering, Appl. Surf. Sci. 254 (2007) 989-992. doi:10.1016/j.apsusc.2007.08.085.

[13] W. Löschau, R. Lenk, Rapid Prototyping of Complex-Shaped Parts of Si/SiC-Ceramics by Laser Sintering, in: Ceram. - Process. Reliab. Tribol. Wear, Wiley-VCH Verlag GmbH \& Co. KGaA, Weinheim, FRG, 2006: pp. 145-149. doi:10.1002/3527607293.ch24.

[14] K. Shahzad, J. Deckers, J.-P. Kruth, J. Vleugels, Additive manufacturing of alumina parts by indirect selective laser sintering and post processing, J. Mater. Process. Technol. 213 (2013) 1484-1494. doi:10.1016/j.jmatprotec.2013.03.014.

[15] Y. Wu, J. Du, K.-L. Choy, L.L. Hench, Laser densification of alumina powder beds generated using aerosol assisted spray deposition, J. Eur. Ceram. Soc. 27 (2007) 47274735. doi:10.1016/j.jeurceramsoc.2007.02.219. 
[16] C.-J. Bae, J.W. Halloran, Influence of Residual Monomer on Cracking in Ceramics Fabricated by Stereolithography, Int. J. Appl. Ceram. Technol. 8 (2011) 1289-1295. doi:10.1111/j.1744-7402.2010.02578.x.

[17] T. Chartier, C. Duterte, N. Delhote, D. Baillargeat, S. Verdeyme, C. Delage, et al., Fabrication of Millimeter Wave Components Via Ceramic Stereo- and Microstereolithography Processes, J. Am. Ceram. Soc. 91 (2008) 2469-2474. doi:10.1111/j.1551-2916.2008.02482.x.

[18] T.-M.G. Chu, D.G. Orton, S.J. Hollister, S.E. Feinberg, J.W. Halloran, Mechanical and in vivo performance of hydroxyapatite implants with controlled architectures, Biomaterials. 23 (2002) 1283-1293. doi:10.1016/S0142-9612(01)00243-5.

[19] Z.C. Eckel, C. Zhou, J.H. Martin, A.J. Jacobsen, W.B. Carter, T.A. Schaedler, Additive manufacturing of polymer-derived ceramics., Science. 351 (2016) 58-62. doi:10.1126/science.aad2688.

[20] M. Allahverdi, S.. Danforth, M. Jafari, A. Safari, Processing of advanced electroceramic components by fused deposition technique, J. Eur. Ceram. Soc. 21 (2001) 1485-1490. doi:10.1016/S0955-2219(01)00047-4.

[21] T. Schlordt, S. Schwanke, F. Keppner, T. Fey, N. Travitzky, P. Greil, Robocasting of alumina hollow filament lattice structures, J. Eur. Ceram. Soc. 33 (2013) 3243-3248. doi:10.1016/j.jeurceramsoc.2013.06.001.

[22] T. Schlordt, P. Greil, Robocasting of alumina lattice truss structures, J. Ceram. Sci. Technol. 3 (2012) 81-88.

[23] E. Özkol, W. Zhang, J. Ebert, R. Telle, Potentials of the "Direct inkjet printing" method for manufacturing 3Y-TZP based dental restorations, J. Eur. Ceram. Soc. 32 (2012) 2193-2201. doi:10.1016/j.jeurceramsoc.2012.03.006.

[24] X. Zhao, J.R.G. Evans, M.J. Edirisinghe, J.-H. Song, Direct Ink-Jet Printing of Vertical Walls, J. Am. Ceram. Soc. 85 (2002) 2113-2115. doi:10.1111/j.1151- 
2916.2002.tb00414.x.

[25] X. Zhao, J.R.G. Evans, M.J. Edirisinghe, J.H. Song, Ink-jet printing of ceramic pillar arrays, J. Mater. Sci. 37 (2002) 1987-1992. doi:10.1023/A:1015247131016.

[26] C. Ainsley, N. Reis, B. Derby, Freeform fabrication by controlled droplet deposition of powder filled melts, J. Mater. Sci. 37 (2002) 3155-3161. doi:10.1023/A:1016106311185.

[27] M. Lejeune, T. Chartier, C. Dossou-Yovo, R. Noguera, Ink-jet printing of ceramic micro-pillar arrays, J. Eur. Ceram. Soc. 29 (2009) 905-911. doi:10.1016/j.jeurceramsoc.2008.07.040.

[28] A. Khalyfa, S. Vogt, J. Weisser, G. Grimm, A. Rechtenbach, W. Meyer, et al., Development of a new calcium phosphate powder-binder system for the 3D printing of patient specific implants, J. Mater. Sci. Mater. Med. 18 (2007) 909-916. doi:10.1007/s10856-006-0073-2.

[29] L. Schlier, W. Zhang, N. Travitzky, P. Greil, J. Cypris, M. Weclas, Macro-Cellular Silicon carbide Reactors for Nonstationary Combustion Under Piston Engine-Like Conditions, Int. J. Appl. Ceram. Technol. 8 (2011) 1237-1245. doi:10.1111/j.17447402.2010.02591.x.

[30] Z. Fu, L. Schlier, N. Travitzky, P. Greil, Three-dimensional printing of SiSiC lattice truss structures, 2013. doi:10.1016/j.msea.2012.09.107.

[31] Y. Bai, C.B. Williams, An exploration of binder jetting of copper, Rapid Prototyp. J. 21 (2015) 177-185. doi:10.1108/RPJ-12-2014-0180.

[32] J.A. Gonzalez, J. Mireles, Y. Lin, R.B. Wicker, Characterization of ceramic components fabricated using binder jetting additive manufacturing technology, Ceram. Int. 42 (2016) 10559-10564. doi:10.1016/j.ceramint.2016.03.079.

[33] R. Melcher, S. Martins, N. Travitzky, P. Greil, Fabrication of Al2O3-based composites by indirect 3D-printing, 2006. doi:10.1016/j.matlet.2005.09.059. 
[34] X. Yin, N. Travitzky, R. Melcher, P. Greil, Three-dimensional printing of TiAl3/Al2O3 composites, Zeitschrift Für Met. 97 (2006) 492-498. doi:10.3139/146.101263.

[35] C.R. Rambo, N. Travitzky, K. Zimmermann, P. Greil, Synthesis of TiC/Ti-Cu composites by pressureless reactive infiltration of $\mathrm{TiCu}$ alloy into carbon preforms fabricated by 3D-printing, 2005. doi:10.1016/j.matlet.2004.11.051.

[36] N. Frage, L. Levin, E. Manor, R. Shneck, J. Zabicky, Iron-titanium-carbon system. I. Equilibrium between titanium carbide $(\mathrm{TiCx})$ of various stoichiometries and ironcarbon alloys, Scr. Mater. 35 (1996) 791-797. doi:10.1016/1359-6462(96)00229-1.

[37] V. Moisy-Maurice, N. Lorenzelli, C.H. De Novion, P. Convert, High temperature neutron diffraction study of the order-disorder transition in TiC1-x, Acta Metall. 30 (1982) 1769-1779. doi:10.1016/0001-6160(82)90093-1.

[38] S. Sarian, Diffusion of 44Ti in TiCx, J. Appl. Phys. 40 (1969) 3515-3520. doi:10.1063/1.1658229.

[39] S.S. Ordan'yan, G.S. Tabatadze, L. V. Kozlovskii, Densieication of nonstoichiometric titanium carbide during sintering, Sov. Powder Metall. Met. Ceram. 18 (1979) 458-461. doi:10.1007/BF00797248.

[40] E.K. Storms, The refractory carbides, Academic Press, New York, 1967.

[41] M.P. Dariel, Enhanced Mass Transport in Titanium Carbide at Large Departures from Stoichiometry, Powder Metall. Met. Ceram. 42 (2003) 460-467. doi:10.1023/B:PMMC.0000013217.41185.fb. 


$$
\text { of e e r }
$$

